\title{
2 Politics and the resilience of ecosystem services
}

\author{
Michael L. Schoon, Martin D. Robards, \\ Katrina Brown, Nathan Engle, Chanda L. Meek \\ and Reinette Biggs ${ }^{1}$
}

\begin{abstract}
SUMMARY
Different sectors of society typically value, need and demand different bundles of ecosystem services. At the same time, important trade-offs exist between the production of different services, and it is not possible to increase the resilience of all ecosystem services simultaneously. Decisions about which services to sustain in a particular social-ecological system therefore require trade-offs that are inherently political. Politics can be described as 'the authoritative allocation of values for a society' (Easton 1965). To further complicate matters, the desired mix of services will evolve with changing societal values and preferences, and the resilience of ecosystem services is only one among many desired outcomes (e.g. equality, human rights, democracy) of social-ecological systems. Resolving these trade-offs requires resolution of collective-action dilemmas and intergroup conflicts, a process that comes replete with power inequalities, asymmetric resource bases and unequal outcomes. This chapter discusses some of the asymmetries and power dynamics that underlie decisions of which ecosystem services should form the focus for resilience building initiatives; the remainder of the book assumes these choices
\end{abstract}

The findings, interpretations, and conclusions expressed in this publication are those of the author(s) and should not be attributed in any manner to The World Bank, its Board of Executive Directors, or the governments they represent.

Principles for Building Resilience: Sustaining Ecosystem Services in Social-Ecological Systems, eds R. Biggs, M. Schlüter and M. L. Schoon. Published by Cambridge University Press. (C) Cambridge University Press 2015. 
have been made and focuses on how the resilience of some agreed-on mix of ecosystem services may be enhanced. Here, we focus specifically on the social consequences of trade-offs between ecosystem services; asymmetries in the distribution of ecosystem services; and we briefly discuss the broad literature of how these may be addressed through wider deliberative processes. We find that issues associated with the allocation of ecosystem services are poorly integrated into the resilience literature, and suggest that an improved understanding of allocation trade-offs could result from more applied research on use of ecosystem services that integrates perspectives from the social sciences about how and why people make and respond to decisions concerning ecosystem services.

\section{I INTRODUCTION}

Prompted by escalating rates of environmental change, resilience thinking is one emerging applied field that explicitly seeks to inform managers and policy-makers in the governance of social-ecological systems (SES) and the ecosystem services they produce (Berkes et al. 2000; Walker and Salt 2006). Much of this research has moved beyond the dichotomous separation of social and ecological systems, toward studying coupled or linked SES. It also moves away from traditional top-down management approaches, premised on static or linear notions of ecosystems and social organization. The research incorporates greater attention to the existence of multiple possible ecosystem and social states or regimes, the possibility of rapid non-linear change, linkages across and among scales, and the idea that different SES states and their associated ecosystem services benefit different groups of people (Holling and Meffe 1996; MA 2005) (Chapter I).

This chapter analyses some of the important political and power dimensions inherent in the governance of SES and the implicit or explicit societal choices about which sets of ecosystem services to build resilience of, and try to sustain, in the face of disturbance and change. Any particular set of ecosystem services for which we build resilience will involve trade-offs - both between actor groups 
and between different bundles of ecosystem services - with decisions influenced (to a greater or lesser extent) by issues of power and inequality. Blindly applying the principles put forward in this book may accomplish some groups' goals, but may also intensify ecosystem-service trade-offs and power differentials. While these issues are ubiquitous to the process of political decision-making, this chapter seeks to highlight the political and power dimensions that can influence the selection of specific sets of ecosystem services to build resilience of, and to emphasize the need to reflect on these issues before applying the principles put forward in this remainder of this book.

In particular, we emphasize the inherent danger in ecosystem governance approaches that do not incorporate and consider the social mechanisms by which governance and institutions accomplish their goals (Hatt 2012; Brown and Westaway 2011). Any set of ecosystem services 'chosen' as the focus for resilience-building initiatives is an emergent outcome resulting from both explicitly and implicitly political processes. Too often, initiatives aimed at building resilience do not consider the existing socio-political inequalities in the system, and the extent to which strategies aimed at building resilience may reinforce and aggravate these disparities and inequalities. This does not mean that perfect equality is achievable, but rather that increasing levels of inequality may reach dangerous levels. Scientists themselves may contribute to the problem if an overly technocratic approach is adopted and societal goals are not more widely deliberated. While scientific analyses may provide valuable information about the different magnitude and mix of ecosystem services that might be provided by different SES states, this information does not necessarily make clear what SES states and ecosystem services are most desirable, nor is the aim of scientific analysis to do so. Choosing to build resilience of a particular set of ecosystem services reflects an implicit valuation of a specific set of services by specific groups of people at particular times and places, and either explicitly (or not) includes the inherent trade-offs that accompany those choices. Consequently, 
Carpenter et al. (2001) caution that resilience of such a chosen set of services is a 'normative concept' and Armitage and Johnson (2006, p. 14) urge that consideration of resilience under such circumstances should be 'situated in the context of contested and evolving human interests and the uncertainties of human interaction.' Ultimately, all initiatives aimed at building resilience of ecosystem services have distributional implications, and are a matter of justice within and between generations (Norgaard 2010).

Throughout the rest of the book, we focus on general principles that might be employed to build resilience of different sets of ecosystem services, and assume that some process has been followed to arrive at the selected one. We do not define this 'desired' set of ecosystem services, as it will vary between places and groups, and change over time as societal preferences change. Here, we emphasize the critical necessity of reflecting on the implicit or explicit choice about which ecosystem services to build resilience of before attempting to apply any of the principles. In this way we ensure that initiatives aimed at building such resilience of ecosystem services do not simply advance and entrench the position of more powerful groups in society. To do so, this chapter first discusses some of the trade-offs between ecosystem services implicit in building resilience for a given set of ecosystem services. We then explore the challenges and repercussions of distribution that result from these trade-offs. Finally, we highlight some asymmetries and how these may be reduced to increase legitimacy in the selection of ecosystem services that can, in turn, provide greater support for maintaining specific sets of ecosystem services.

\subsection{THE TRADE-OFFS OF SELECTING BETWEEN BUNDLES OF ECOSYSTEM SERVICES}

Different bundles of ecosystem services often trade off against one another, and the selection of one bundle may eliminate the possibility for the production of other bundles of ecosystem services, as highlighted in Box 2.1 (MA 2005; Bennett et al. 2009) (Chapter 1). For instance, the preservation of global biodiversity as a public good 


\section{BOX 2.I Ecosystem services and community-based conservation in the Richtersveld National Park, Southern Africa}

Community-based conservation ( $\mathrm{CBC})$, promoting local participation and sustainable use of resources, arose in the 1990s as a response to failures of top-down command and control approaches to conservation. Paralleling the discourse in this chapter, past conservation efforts often reinforced deep power asymmetries of groups favouring different bundles of ecosystem services. In the case of protected areas, the global conservation movement led by international environmental NGOs and their supporters pushed for greater protection of biodiversity at a global scale and, in support of financial sustainability of parks, advocated for ecotourism within the parks. However, this collection of ecosystem services often came at the expense of local resource users. While CBC should not be viewed as a panacea, and local communities as a romanticized, homogeneous group in sustainable balance with nature, we do see instances where broader participation assuages some of the trade-offs of ecosystem services identified in the chapter.

In |Ai-|Ais/Richtersveld Transfrontier Park, straddling the border of Namibia and South Africa (Fig. 2.1), initial management followed top-down conservation methods. Although Richtersveld National Park in South Africa, created in 1991, arose out of the settlement of land claims between the local community and the national government and the creation of a contractual park, restrictions to local users often meant closing access to grazing of sheep and goats as well as the collection of other resources. In the words of the park manager, 'tourists won't pay to see goats' (personal communication, 2008). Once again, biodiversity conservation goals and tourist expectations trumped local ecosystem-service decisions. Yet this approach to conservation comes with well-known drawbacks. Resource restrictions may compound poverty and worsen subsistence viability. For these reasons as well as basic concepts of equality, it often lacks legitimacy in the surrounding communities. In turn, monitoring and enforcement of regulations and restrictions becomes difficult, expensive and often ineffective. Through the contractual park, in which the local community owned the land and collaboratively managed the park with the 


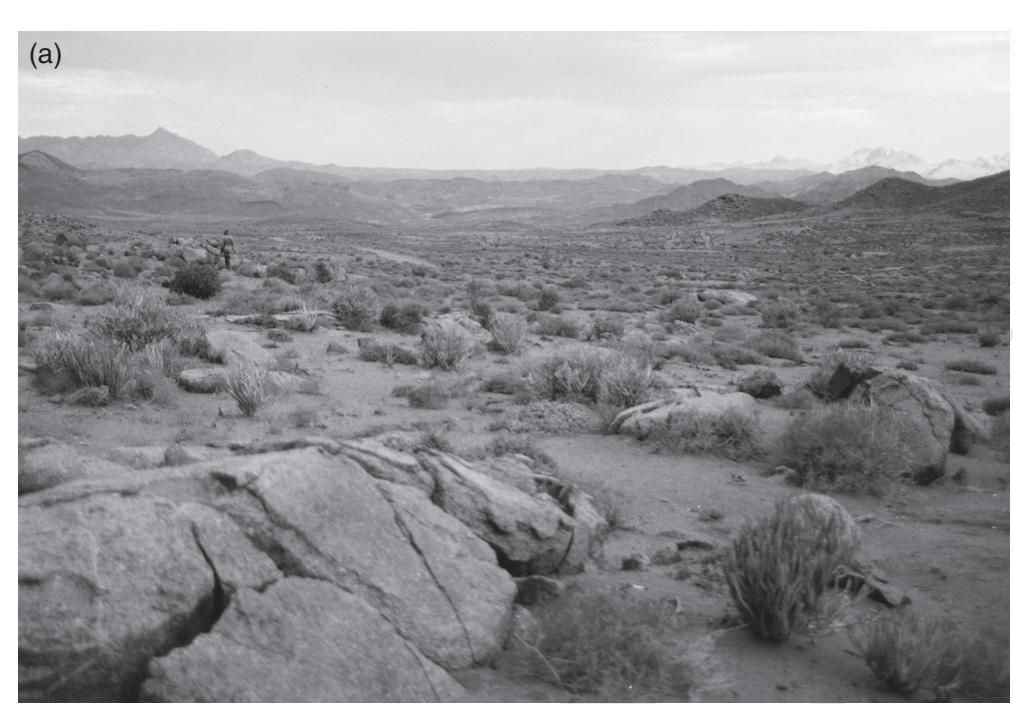

(b)

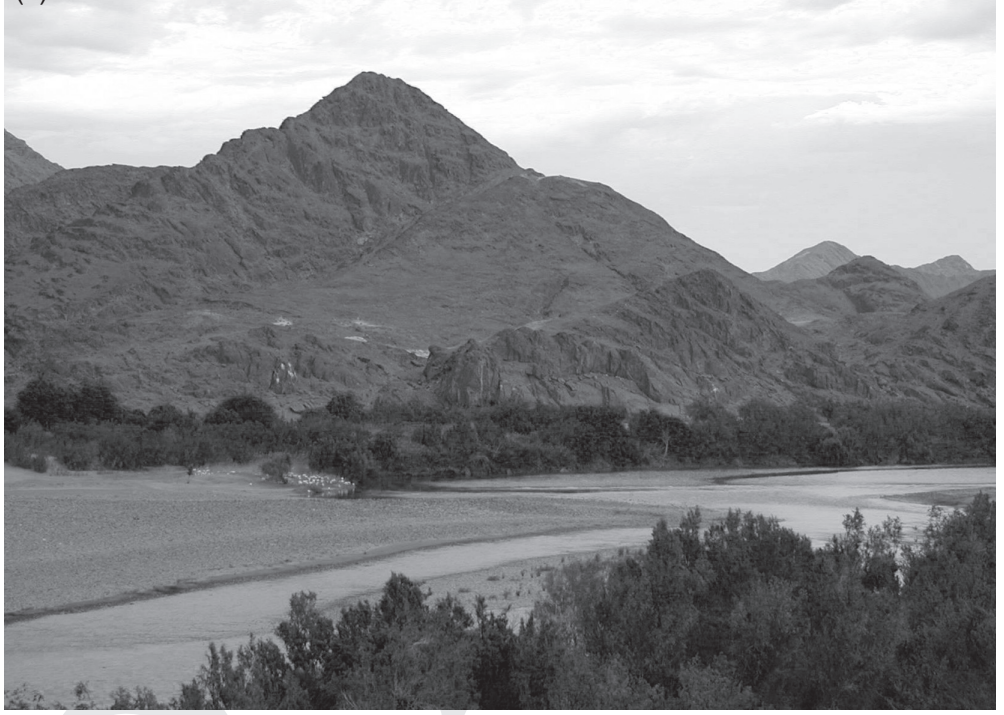

FIG. 2.I (a) The Succulent Karoo ecosystem of |Ai-|Ais/Richtersveld Transfrontier Park looks harsh but is home to high biodiversity richness and a suite of ecosystem services. (b) The Orange or Gariep River forms the international boundary between Namibia and South Africa and forms a political divide in the ecosystem, separating |Ai-|Ais Hot Springs from Richtersveld National Park. Photo credits: Christo Fabricius 


\section{BOX 2.I Continued}

South African National Parks Board, the local Nama people and park officials began a deliberative process regarding access, use and management of natural resources. As a result of this deliberation, grazing was again allowed back in the park.

As community members became more involved in a conservation initiative of their own development, they became emboldened and created Richtersveld Cultural and Botanical Landscape, a community conservancy. In 2007, the conservancy was granted UNESCO World Heritage status. World Heritage status was granted with 'the traditional land-use system of the Nama ... seen as part of the protection system' (whc.unesco.org). Specifically, the sustainable resource use of the transhumance grazing practices and the traditional use of grass for portable thatched roof housing were seen as integral elements to the cultural landscape. In effect, deliberation with the park service and self-determination put in place a series of events at the time of this writing and a dramatic shift in resource rules from strict restriction to increased access to a celebration of sustainable resource use.

advocated by predominantly Western environmental advocacy groups through increasing the area of national parks and minimizing resource extraction reduces the land available for subsistence use as arable land or as a source of food, lodging or medicinal products (Robards et al. 2011). Similarly, the creation of palm-oil plantations to cater to the global demand for oil products decreases the carbon sequestration possibilities of old-growth tropical forests (Butler et al. 2009). In such cases one set of ecosystem services reduces or obviates the possibility of other sets, and a dilemma emerges in that different groups of people benefit from one selection as opposed to another. These trade-offs can perpetuate the dispossession of lands and resources initiated during the era of European colonialism, and further the logic of enclosure in which resources formerly held in common become privatized commodities (Heynen and Robbins 2005). 
The desired allocation or prioritization of ecosystem services at one level or scale often has direct trade-offs and may be radically opposed at another scale. For instance, the provision of wild meats in tropical forests at a local level may be essential for communities, but may be counter to global biodiversity goals; swidden (shifting cultivation) agriculture may sustain local economic or nutritional needs, but minimize global climate mitigation actions; and laissez-faire planning and urban sprawl may benefit local governments, but work against global goals for the reduction of fossil-fuel consumption. Such trade-offs may be accentuated by differing worldviews or cultures.

Because it is usually not possible to meet all societal needs and expectations, we must acknowledge that any particular set of ecosystem services involves trade-offs with other options. Usually these trade-offs are biased in favour of particular groups, or can only be mitigated through acknowledging the special interests of specific groups in society. Examples include the mitigation of global greenhouse-gas emissions by more powerful countries through capture of forest resources in tropical low- and middle-income countries, which may perpetuate poverty traps in which systemic influences reinforce the root causes of poverty through the control of resource access and use (Sachs 2005) or create them as a collateral repercussion of not wishing to bear the economic burden of emission reductions (Dow et al. 2006). In these ways, emission reduction efforts may lead to poverty traps similar to those arising from some past biodiversity conservation efforts (Adams et al. 2004), where access to resources by local communities may be restricted, leading to further impoverishment.

These examples demonstrate how trade-offs between ecosystem services can have significant social consequences. Selecting particular sets of ecosystem services can result in a number of ramifications that may reinforce the inequalities that led to those choices. In the following section, we draw further attention to such distributional questions that often arise from the trade-offs of ecosystem services. 


\subsection{THE CHALLENGES OF DistRibUtion}

Distributional challenges emerge when certain groups of people have disproportionate and inequitable benefits from the selection of specific sets of ecosystem services. These benefits are often linked to the fact that those who benefit from the ecosystem services may institute rules, which give them access to these ecosystem services while other groups are precluded. For example, a Kenyan coastal SES's restrictions on fishing gear - specifically use of seine nets - aimed at conserving the fishery and building ecosystem resilience, have important socially differentiated impacts. In particular, women fish traders are disadvantaged as their access to small, cheap fish is undermined, thus eroding their livelihood opportunities and negotiating capabilities in setting access rules to the fishery (Daw et al. 2012).

Bundles of ecosystem services and related governing institutions are often directly affected by, if not products of, historical institutions relating to property rights, land-use decisions, and the logic of appropriateness in resource use. Prior conditions and constraints may maintain a strong influence on contemporary ecosystem services. As an example, among other policies aimed at reducing pelagic sealing and more closely controlling the scale of early twentieth-century trade in fur seals, the United States restricted indigenous Unangan hunters from using modern technology in their hunt for fur seals. This type of restriction, while originally based on considerations of commerce as much as conservation eventually constituted a major restriction in the name of conservation under numerous international wildlife conventions including the North Pacific Fur Seal Convention of 1911 and the 1946 International Convention for the Regulation of Whaling (Meek 2011).

Human preferences often prioritize provisioning services over regulating services, and both of these are prioritized over cultural and supporting services (Rodriguez et al. 2006). These choices may exacerbate societal inequalities, and not only between different social groups; they also serve to privilege an immediate time horizon over 
a more sustainable long-term perspective, and current generations over future generations. For instance, lasting soil conservation and the minimization of dongas (dried, eroded waterways) through pasture rotation and limits on livestock often lacks support amongst local herders when they compare this to wealth maximization as measured by herd size in parts of southern Africa (Doran et al. 1979). While current generations may benefit from the increased cattle numbers, the loss of productive land can substantially reduce the potential of future generations to make a living.

Scientists may further complicate distributional trade-offs between societal groups by exerting power and influence through scientization of a political problem, often unknowingly or unintentionally using science to mask their own interests (Habermas 1970). Scientization suppresses the open discussion of value preferences and delegitimizes those without a scientific perspective to support their position. This often marginalizes those unable to speak the specialized language of science, which often includes the disenfranchised who bear the brunt of the negative trade-offs /Gismondi and Richardson 1991; Lemos 2003; Sarewitz 2004). In juxtapose, politicization is when people - whether scientists, (non-governmental organizations (NGOs), private industries or others - manipulate science to fit their desired political or legal interests (Joly et al. 2010). Politicians are not the only actors who can politicize science, as scientists can also use science to defend and pursue their own political interests (Pielke 2004). Politicization can inhibit corrective feedbacks that enable SES governance to respond to and incorporate different viewpoints or new scientific understanding.

Promotion of certain sets of ecosystem services by more powerful sectors of society results in a number of ramifications that may reinforce the inequalities that led to specific choices. These distributional disputes often result in strengthening the status quo. The conclusion of work focusing on ecosystem-service trade-offs is the need to find a balance among services to accomplish the 'greater good' (e.g. Nelson et al. 2009; Palumbi et al. 2009). However, this is 
no easy task. The following section discusses responses to emergent asymmetries and means for alleviating them, potentially providing a more legitimate and sustainable system.

\subsection{RESPONDING TO EMERGENT ASYMMETRIES}

At a landscape level, any initiatives to build resilience of ecosystem services entails implicit trade-offs, because it necessarily needs to privilege certain ecosystem services, and different groups of people will benefit to greater or lesser extents. As in many complex systems, there is no optimal set of ecosystem services or real-world Pareto frontier whereby no one can be made better off without someone else being worse off as a result (Levin 2002). Issues of equity and justice can be balanced to varying degrees, but not optimized due to their normative nature. The resultant discord between desired outcomes and the specific combination of ecosystem services that are captured by individuals, communities or society in general, will produce asymmetric gaps as described by Lasswell and Kaplan (1950).

In prioritizing specific sets of ecosystem services, care must be given to ensuring that society builds resilience to a fair and equitable set of ecosystem services rather than entrenching the positions of a privileged few - or risk both moral (e.g. human rights (Hardin 1998)) and practical (e.g. revolution (Scott, 1998, 2009)) repercussions. Institutions that remove people's access to, or use of a specific service, need to more explicitly attend to what these people will do in response, and if they have the capacity and agency to adapt to or buffer that scarcity. History runs rife with examples of not attending to these questions. Although the very construct of ecosystem services implies a substitutable commodity rather than an outcome of contestation and historical paths, at the same time it may allow considerable transparency in evaluating trade-offs that might otherwise be taken for granted.

One means of building a more legitimate and broadly acceptable choice of ecosystem services is through broader deliberation. More fully deliberating the 'desirability' of ecosystem services in SES may not only balance competing conceptualizations of 'desirability', but 
can build further benefits toward sustainability or resilience of ecosystem services. It is here that long-standing philosophical debates (e.g. Hobbes, Foucault, Habermas) can be drawn upon in a process of social learning as well as the work of deliberative democracy scholars (Dewey 1927; Rawls 1993; Dryzek 2002), as we collectively seek to find legitimate sustainable relationships with each other and the world around us.

These ideas foreshadow our discussions on building resilience through the principles of learning (P5 - Learning), broader levels of participation (P6 - Participation) and innovative governance arrangements such as polycentricity (P7 - Polycentricity). The notion that participation leads to more resilient provision of ecosystem services stems in part from increasing legitimacy of the political process of selecting which ecosystem services to build resilience of. Increased participation also results in more respected monitoring and enforcement, as well as a means to change inequitable outcomes through collective choice bargaining (Schlager and Ostrom 1992). Similarly, polycentric governance arrangements allow for learning and experimentation across geographic governance regions as well as a diversity of institutional options (Olsson et al. 2004).

\subsection{THE BENEFITS OF WIDER DELIBERATION}

Ecosystem-service governance outcomes are a result of balancing competing 'desires' of different groups; however, they are influenced by various asymmetries, leading some groups to get closer to their desired goals than others. As we have shown, agency of those in power to self-allocate the flow of ecosystem services may lead them maintaining their short-term benefits and the status quo in terms of inequalities and asymmetries. However, disenfranchisement of specific actors may lead to humanitarian issues or revolt of the disenfranchised. We have argued for the need to explicitly acknowledge trade-offs, distributional issues, and the repercussions of not proactively incorporating the responses of, or repercussions to the disenfranchised - in other words the need to consider appropriately the social ramifications of 
political decision-making when it comes to initiatives to build resilience of ecosystem services. Examples of processes to guide such thinking include companion modelling (Étienne 2011) or recent work on mental models (Biggs et al. 2011) (P4 - CAS thinking).

Openly deliberative processes may better incorporate feedbacks from the marginalized through providing for more inclusion, but will require the more powerful to incorporate pluralistic local needs and values into the dominant paradigms that they seek to maintain. Acting in this manner is no simple matter; however, self-restraint does emerge in governance. For example, constitutions favouring equal opportunity of all citizens may limit a government's ability to provide preferential allocation of resources to specific groups or communities. Establishing the degree to which global desires are being achieved at the cost of local repercussions will better illuminate priorities for action. Numerous authors have indicated that biodiversity goals in the tropics will not be met without addressing poverty first (e.g. Adams et al. 2004). Not only will change require better understanding of feedbacks associated with poverty traps and local agency, it will also need leaders and the elite (at multiple scales from local to global) to recognize these interrelationships, and to work towards more deliberative and open processes. For example, balancing mitigation of climate emissions through Reducing Emissions from Deforestation and Forest Degradation (REDD) in developing countries does not mask the need for comprehensive reductions in carbon emissions by the largest emitters, and may exacerbate poverty, which is inextricably linked to resource access in many regions (Angelson et al. 2009). Ignoring that linkage ignores the full cost of our carbon emissions.

More fully deliberating which ecosystem services should be the focus of resilience building initiatives in SES can not only help balance competing conceptualizations of which ecosystem services society desires to sustain, but can build further benefits toward sustainability. Indeed, as Levin (2010, p. 13) concludes 'one of the great challenges in achieving sustainability will be in understanding the basis for 
cooperation'. Without such an approach, society will struggle to develop a long-term strategy whereby we collectively live within the limits of the globe's ecosystems.

\subsection{CONCLUSION}

This chapter has highlighted some of the deep political issues and social implications underlying initiatives to build resilience of ecosystem services. Before applying the principles discussed in this book to foster the resilience of ecosystem services, critical attention should be directed towards understanding the context, contests, politics and history in which ecosystem services in a particular place are embedded. In particular, the current set of ecosystem services provided by a landscape may reflect deep asymmetries in which sectors or groups in society are supported or favoured, and strengthening the resilience of those ecosystem services may further entrench these inequalities. In some cases, repercussions from the disenfranchised may destabilize a system, while in other cases efforts to reduce inequity may be well-meaning; however, changes to the existing ecosystem-service landscape may generate new conflicts and tradeoffs. Reflecting on these issues can help illuminate who will be favoured or disadvantaged by choices to build resilience of certain sets of ecosystem services, and how this may itself influence the long-term resilience of these ecosystem services. Norgaard (2010, p. 1226) notes that 'while economists have been unusually successful at averting the ethical questions, and in the process supporting those who currently benefit from the governance structure, this avoidance has become central to the problems we now have in reaching a global accord'. The processes we summarize here and elsewhere (Robards et al. 2011) provide examples of what is being avoided and why. Where the flow of ecosystem services cannot fulfil all social and ecosystem needs, the feedbacks we discuss will need to be integrated into governance institutions to ensure that the resilience of ecosystem services is not incrementally eroded, with long-term repercussions for human or ecosystem health. 
Given the diversity of potential ecosystem services and governance arrangements in most SES, the selection of bundles of ecosystem services is a traditional 'wicked' problem in which there can be no overall deliberative panel or institution to decide which ecosystem services should be the focus of resilience-building initiatives (Rittl and Webber 1973). Rather, the 'chosen' set of ecosystem services produced by a social-ecological landscape is an emergent, messy phenomenon that is the outcome of competition and negotiation between many different users and sectors of society at different scales, and the biophysical, economic and institutional constraints of the underlying SES. Social factors and processes shape and are shaped by the set of ecosystem services, in what can sometimes be a reinforcing process. This results in rigidity traps in which systems become highly connected, self-reinforcing and inflexible due to power differentials, sticky institutional arrangements and other mechanisms constraining governance changes, including externalization of trade-offs (Carpenter and Brock 2008). Such traps limit the ability of actors within the system to reorganize interactions, even if such a reorganization would benefit the provision of ecosystem services to society overall (Gunderson and Holling 2002). We have highlighted how trade-offs associated with ecosystem services can result in such traps, and are sometimes exacerbated through the scientization of the political discussion and politicization of scientific knowledge.

In providing these caveats to the resilience-building enterprise, we do not suggest that any decision-makers must have fully contextualized understanding and engage in all of the transaction costs implied in deliberative democratic practice. What is required is a measure of awareness and transparency regarding the political dimensions of potential ecosystem-service choices as well as potential futures for which we can build resilience.

\section{REFERENCES}

Adams, W. M., Aveling, R., Brockington, D. et al. (2004). Biodiversity conservation and the eradication of poverty. Science, 306, 1146-1149. 
Angelsen, A., Brockhaus, M., Kanninen, M., eds. et al. (2009). Realising REDD+: National Strategy and Policy Options. Bogor: Center for International Forestry Research.

Armitage, D. R. and Johnson, D. (2006). Can resilience be reconciled with globalization and the increasingly complex conditions of resource degradation in Asian coastal regions? Ecology and Society, 11, 2.

Bennett, E. M., Peterson, G. D., Gordon, L. J. (2009). Understanding relationships among multiple ecosystem services. Ecology Letters, 12, 1-11.

Berkes, F., Folke, C., Colding, J., eds. (2000). Linking Social and Ecological Systems: Management Practices and Social Mechanisms for Building Resilience. Cambridge: Cambridge University Press.

Biggs, D., Abel, N., Knight, A. T. et al. (2011). The implementation crisis in conservation planning: could 'mental models' help? Conservation Letters, 4, 169-183.

Brown, K. and Westaway, E. (2011). Agency, capacity, and resilience to environmental change: lessons from human development, well-being, and disasters. Annual Review of Environment and Resources, 36, 321-342.

Butler, R. A., Lian P. K., Jaboury, G. (2009). REDD in the red: palm oil could undermine carbon payment schemes. Conservation letters, 2, 67-73.

Carpenter, S. R. and Brock, W. A. (2008). Adaptive capacity and traps. Ecology and Society, 13, 40.

Carpenter, S. R., Walker, B., Anderies, J. M., Abel, N. (2001). From metaphor to measurement: resilience of what to what? Ecosystems, 4, 765-781.

Daw, T., Brown, K., Rosendo, S., Pomeroy, R. (2012). Applying the ecosystem services concept to poverty alleviation: the need to disaggregate human wellbeing. Environmental Conservation, 38, 370-379

Dewey, J. (1927). The Public and its Problems: An Essay in Political Inquiry. New York, NY: Henry Holt Press.

Doran, M. H., Low, A. R. C., Kemp, R. L. (1979). Cattle as a store of wealth in Swaziland: implications for livestock development and overgrazing in eastern and southern Africa. American Journal of Agricultural Economics, $61,41-47$.

Dow, K., Kasperson, R. E., Bohn, M. (2006). Exploring the social justice implications of adaptation and vulnerability. In Fairness in Adaptation to Climate Change. Cambridge, MA: MIT Press, pp. 77-96.

Dryzek, J. (2002). Deliberative Democracy and Beyond: Liberals, Critics, Contestations. Oxford: Oxford University Press.

Easton, D. (1965). A Framework for Political Analysis. Englewood Cliffs, NJ: Prentice-Hall. 
Étienne, M., ed. (2011). Companion Modelling. A Participatory Approach to Support Sustainable Development. Dordrecht: Springer.

Gismondi, M. and Richardson, M. (1991). Discourse and power in environmental politics: public hearings on a bleached Kraft pulp mill in Alberta, Canada. Capitalism Nature Socialism, 2, 43-66.

Gunderson, L. H. and Holling, C. S., eds. (2002). Panarchy: Understanding Transformations in Human and Natural Systems. Washington, DC: Island Press. Habermas, J. (1970). Toward a Rational Society. Boston, MA: Beacon.

Hardin, R. (1988). Morality within the Limits of Reason. Chicago: University of Chicago Press.

Hatt, K. (2012). Social attractors: a proposal to enhance 'resilience thinking' about the social. Society and Natural Resources, 26, 30-43.

Heynen, N. and Robbins, P. (2005). The neoliberalization of nature: governance, privatization, enclosure and valuation. Capitalism, Nature, Socialism, $16,5-8$.

Holling, C. S. and Meffe, G. K. (1996). Command and control and the pathology of natural resource management. Conservation Biology, 10, 328-337.

Joly, J., Reynolds, J., Robards, M. D. (2010). Recognizing when the 'best scientific data available' isn't. Stanford Environmental Law Journal, 29, 247-282.

Lasswell, H. D. and Kaplan, A. (1950). Power and Society: A Framework for Political Inquiry. New Haven, CT: Yale University Press.

Lemos, M. C. (2003). A tale of two policies: the politics of climate forecasting and drought relief in Ceará, Brazil. Policy Sciences, 36, 101-123.

Levin, S. A. (2002). Complex adaptive systems: exploring the known, the unknown, and the unknowable. Bulletin of the American Mathematical Society, 40, 3-19.

Levin, S. A. (2010). Crossing scales, crossing disciplines: collective motion and collective action in the global commons. Philosophical Transactions of the Royal Society, Series B, 365, 13-18.

MA. (2005). Millennium Ecosystem Assessment: Ecosystems and Human WellBeing: A Framework for Assessment. Washington, DC: Island Press.

Meek, C. L. (2011). Conservation of marine mammals in Alaska: the value of policy histories for understanding contemporary change. In North by 2020 Synthesis. Fairbanks, AK: University of Alaska Press, pp. 359-375.

Nelson, E., Mendoza, G., Regetz, J. et al. (2009). Modeling multiple ecosystem services, biodiversity conservation, commodity production, and trade-offs at landscape scales. Frontiers in Ecology and the Environment, 7, 4-11

Norgaard, R. B. (2010). Ecosystem services: from eye-opening metaphor to complexity blinder. Ecological Economics, 69, 1219-1227. 
Olsson, P., Folke, C., Berkes, F. (2004). Adaptive comanagement for building resilience in social-ecological systems. Environmental Management, 34, 75-90.

Palumbi, S. R., Sandifer, P. A., Allan, J. D. et al. (2009). Managing for ocean biodiversity to sustain marine ecosystem services. Frontiers in Ecology and the Environment, 7, 204-211.

Pielke Jr., R. A. (2004). When scientists politicize science: making sense of controversy over The Skeptical Environmentalist. Environmental Science and Policy, 7, 405-417.

Rawls, J. (1993). Political Liberalism, 4th edn. New York, NY: Columbia University Press.

Rittel, H. W. J. and Webber, M. M. (1973). Dilemmas in a general theory of planning. Policy Sciences, 4, 155-169.

Robards, M. D., Schoon, M. L., Meek, C. L., Engle, N. L. (2011). The importance of social drivers in the resilient provision of ecosystem services. Global Environmental Change, 21, 522-529.

Rodriguez, J. P., Beard, Jr., T. D., Bennett, E. M. et al. (2006). Trade-offs across space, time, and ecosystem services. Ecology and Society, 11, 28.

Sachs, J. (2005). The End of Poverty: How We Can Make It Happen in Our Lifetime. London: Penguin UK.

Schlager, E. and Ostrom, E. (1992). Property-rights regimes and natural resources: a conceptual analysis. Land Economics, 68, 249-262.

Scott, J. C. (1998). Seeing Like a State: How Certain Schemes to Improve the Human Condition Have Failed. Yale, CT: Yale University Press.

Scott, J. C. (2009). The Art of Not Being Governed: An Anarchist History of Upland Southeast Asia. Yale, CT: Yale University Press.

Sarewitz, D. (2004). How science makes environmental controversies worse. Environmental Science and Policy, 7, 385-403.

Walker, B. and Salt, D. (2006). Resilience Thinking: Sustaining Ecosystems and People in a Changing World. Washington, DC: Island Press. 